\title{
Bisphenol-Free Epoxy Resins Derived from Natural Resources Exhibiting High Thermal Conductivity ${ }^{\dagger}$
}

\author{
Matthias Sebastian Windberger 1,2, Evgenia Dimitriou ${ }^{1}$ and Frank Wiesbrock 1,* \\ 1 Polymer Competence Center Leoben GmbH, Roseggerstrasse 12, 8700 Leoben, Austria; \\ matthias.windberger@pccl.at (M.S.W.); evgenia.dimitriou@pccl.at (E.D.) \\ 2 Institute for Chemistry and Technology of Materials, Graz University of Technology, NAWI Graz, \\ Stremayrgasse 9, $8010 \mathrm{Graz}$, Austria \\ * Correspondence: frank.wiesbrock@pccl.at; Tel.: +43-3842-42962-42 \\ + Presented at the First International Conference on "Green" Polymer Materials 2020, 5-25 November 2020; \\ Available online: https://cgpm2020.sciforum.net/.
}

Citation: Windberger, M.S.; Dimitriou, E.; Wiesbrock, F. Bisphenol-Free Epoxy Resins Derived from Natural Resources Exhibiting High Thermal Conductivity. Proceedings 2021, 69, 18. https://doi.org/10.3390/CGPM 2020-07160

Published: 3 November 2020

Publisher's Note: MDPI stays neutral with regard to jurisdictional claims in published maps and institutional affiliations.

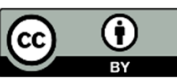

Copyright: $@ 2020$ by the authors. Licensee MDPI, Basel, Switzerland. This article is an open access article distributed under the terms and conditions of the Creative Commons Attribution (CC BY) license (http://creativecommons.org/licenses/by/4.0/).

\begin{abstract}
Polymers commonly have low thermal conductivity in the range of $0.1-0.2 \mathrm{~W} \cdot \mathrm{m}^{-1} \cdot \mathrm{K}^{-1}$, which is a limiting factor for their usage in the course of continuously increasing miniaturization and heat generation in electronic applications. Two strategies can be applied to increase the transport of phonons in polymers: (i) the embedment of thermally conductive inorganic materials and (ii) the involvement of aromatic units enabling anisotropy by $\pi-\pi$ stacking. In this study, the thermal conductivity of resins based on bisphenol A diglycidyl ether BADGE and 1,2,7,8-diepoxyoctane DEO was compared. DEO can be derived from pseudo-pelletierine, which is contained in the bark of the pomegranate tree. The epoxy compounds were cured with isophorone diamine IPDA, $o$-dianisidine DAN, or mixtures of the both diamines. Notably, isophorone diamine is derived from isophorone of which the latter naturally occurs in cranberries. The formulations were produced without filler or with $5 \mathrm{wt}$. $\%$ of $\mathrm{SiO}_{2}$ nanoparticles. Significantly enhanced thermal conductivity in the range of $0.4 \mathrm{~W} \cdot \mathrm{m}^{-1} \cdot \mathrm{K}^{-1}$ occurs only in DEO-based polymer networks that were cured with DAN (and do not contain $\mathrm{SiO}_{2}$ fillers). This observation is argued to originate from $\pi-\pi$ stacking of the aromatic units of DAN enabled by the higher flexibility of the aliphatic carbon chain of DEO compared to that of BADGE. This assumption is further supported by the facts that significantly improved thermal conductivity occurs only above the glass-transition temperature and that nanoparticles appear to disrupt the $\pi-\pi$ stacking of the aromatic groups. In summary, it can be argued that the bisphenol-free epoxy/amine resin with an epoxy compound derivable from natural resources shows favorably higher thermal conductivity in comparison to the petrol-based epoxy/amine resins.
\end{abstract}

Keywords: polymers from natural resources; bisphenol-free epoxy resins; crosslinked polymers; thermal conductivity; $\pi-\pi$ stacking

\section{Introduction}

Polymers are indispensable components for electronic applications such as high-voltage technology and microelectronics [1]. In addition to the electrical insulation properties, their potential lies in their diverse properties such as easy processability, durability, good availability, mechanical properties, or thermal and chemical resistance [2-4]. For diverse applications of polymers in the electronic industry, such as parts in microchips, the challenge arises from removing the heat generated during operation. Moore's law, which, according to current calculations, is coming to an end soon, shows that the number of transistors on a computer chip doubles every two years [5]. There is a direct correlation between the number of transistors and the generation of thermal energy. With this miniaturization and, above all, the continuing complexity in electronic components, the challenge of sufficient heat transport becomes apparent, as active cooling elements reach their 
technical limits due to the fact that components are often difficult to access. In this regard, there is a need to use the highest possible thermal conductivity of all materials used in the electronic component, such that the formation of thermally insulating barrier layers is minimized [6].

For the electronic industry, epoxides have become the electrical insulation materials of choice due to their availability, low cost production, and temperature resistance. Curable epoxy thermosets, which usually consist of bivalent monomers such as bisphenol A diglycidyl ether BADGE, are commonly cured by amines or anhydrides. These curing reactions yield a high network density, mechanical robustness, and temperature stability. Epoxy/amine thermosets show a variety in the choice of available monomers, which allows a wide range of polymer properties to be tailor-fabricated. Due to the high flexibility and easy handling, these thermosets can often be implemented for commercial applications $[7,8]$.

Due to the amorphous structure of polymer chains, epoxides usually exhibit low thermal conductivity in the range of $0.1-0.2 \mathrm{~W} \cdot \mathrm{m}^{-1} \cdot \mathrm{K}^{-1}$ [9]. Nonetheless, thermal conduction and electrical insulation are basic requirements for polymer-based dielectrics in modern electronic applications. Various strategies to increase the thermal conductivity can be applied. The traditional approach is the preparation of epoxy-based composites [10-12]. It should be noted that the increase of the thermal conductivity should not coincide with the deterioration of electrical insulation properties, such as a change in permittivity due to the use of unsuitable fillers [13]. It is effective to add ceramic fillers with high thermal conductivity such as nitrides [14,15], oxides [16,17], or carbides [18,19], since phonons can be transported across the crystal lattice of the particles regardless of the amorphous structure of the epoxide. Hexagonal boron nitride $\mathrm{hBN}$ or diamond show exceptionally high thermal conductivity $[20,21]$. It should be noted that factors such as particle distribution, particle content, or particle shape have enormous influence on the actual heat transfer of the system, as the proximity of the heat-conducting components is a basic requirement (percolation threshold) [22,23]. In addition, the arrangement of polymer chains at the interface of polymers and nanoparticles has been reported [24,25], which can lead to the formation of semi-crystalline regions with enhanced conduction of phonons.

Further measurements aiming to enhance the thermal conductivity can be taken with regard to the chain arrangement within the polymer matrix [26]; semi-crystalline areas potentially enhance the thermal conductivity due to optimized molecular arrangement. One prominent example are aromatic units, which are arranged according to $\pi-\pi$ stacking of the ring structures, yielding anisotropic units with increased thermal conductivity. Especially biphenyl units appear to have a great potential in the formation of anisotropic units that enhance the thermal conductivity [27-29].

The amount of data of a combined effect of inorganic fillers and the presence of inorganic units is still limited [30,31]. In this study, the synergism/antagonism of this approach was investigated with particular consideration of the flexibility of the structural motifs of the polymer chain. In addition, the monomers' origin from renewable resources was addressed: In addition to (comparably less flexible) BADGE, 1,2,7,8-diepoxyoctane DEO, which can be derived from pseudo-pelletierine (contained in the bark of the pomegranate tree), was investigated as diepoxy compound. These epoxy compounds were cured with amines, namely isophorone diamine IPDA and $o$-dianisidine DAN. Isophorone diamine is synthesized from isophorone, the latter of which naturally occurs in cranberries. As inorganic filler, silica nanoparticles were used.

\section{Experiments}

Materials and Instrumentation. DEO (>97\%) and DAN (>98\%) were acquired from TCI (Eschborn, Deutschland). BADGE (97\%), IPDA ( $>98 \%)$, and $\mathrm{SiO}_{2}$ nanopowder (5-15 nm) were purchased from Sigma Aldrich (Vienna, Austria). All chemicals were used without further purification. Glass-transition temperatures were determined utilizing a Perkin 
Elmer Simultaneous Thermal Analyzer (STA) 6000. A heating rate of $20 \mathrm{~K} \cdot \mathrm{min}^{-1}$ was applied. The determination of the thermal conductivity was performed using a Guarded Heat Flow Meter DTC 300. The thermal conductivity measurements were carried out in a temperature range from 30 to $180^{\circ} \mathrm{C}$ in steps of $30 \mathrm{~K}$.

For the preparation of the unfilled and filled test specimens, 1 equiv. of BADGE or DEO was mixed with 1 equiv. of IPDA and DAN in a glass vial, wherein the two amine hardeners were added in the following proportions:

- 0 wt.-\% IPDA; 100 wt.- $\%$ DAN; 1 equiv. of hardener;

- 33 wt.-\% IPDA; 67 wt.-\% DAN; 1 equiv. of hardener;

- 67 wt.-\% IPDA; 33 wt.-\% DAN; 1 equiv. of hardener;

- 100 wt.-\% IPDA; 0 wt.- $\%$ DAN; 1 equiv. of hardener.

Since $o$-dianisidine has a melting point of $137^{\circ} \mathrm{C}$, the monomers as well as the filling molds were pre-heated to $150{ }^{\circ} \mathrm{C}$. For the preparation of nanocomposites, $5 \mathrm{wt} . \mathrm{\%}$ of the inorganic nanoparticles were dispersed in the epoxy compound by sonication for $5 \mathrm{~min}$ prior to heating at $150{ }^{\circ} \mathrm{C}$. By filling the reaction mixtures into steel molds and curing at $150{ }^{\circ} \mathrm{C}$ for $30 \mathrm{~min}$, specimens with a diameter of $50 \mathrm{~mm}$ and height of 2 to $3 \mathrm{~mm}$ were prepared.

\section{Results}

In this study, $2 \times 4 \times 2=16$ different epoxy/amine resins and composites were prepared: This material library was composed of the epoxy compounds BADGE and DEO (2 compounds), which were cured with 100 wt.-\% IPDA, 67 wt.- $\%$ IPDA + 33 wt.- $\%$ DAN, 33 wt.- $\%$ IPDA + $67 \mathrm{wt.} \%$ DAN, or $100 \mathrm{wt.}$ - $\%$ DAN (four ratios) and filled with either 0 or 5 wt.- $\%$ of nano-scaled $\mathrm{SiO}_{2}$ (2 filler contents). The epoxy/amine resins (Figure 1) and composites were cured at $150{ }^{\circ} \mathrm{C}$. Notably, DEO and IPDA can be derived from renewable resources.

Epoxy Compounds

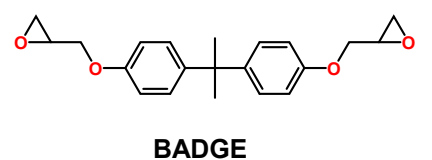

Curing Reaction

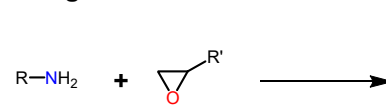

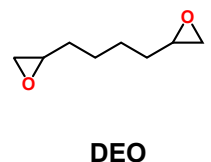

DEO

\section{Amine Compounds}
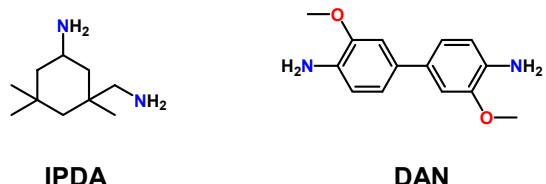

DAN

Figure 1. Top: Chemical structures of the epoxy compounds bisphenol A diglycidyl ether (BADGE) and 1,2,7,8-diepoxyoctane (DEO) as well as the amine compounds isophorone diamine (IPDA) and $o$-dianisidine DAN. Bottom: Curing reaction of epoxy compounds with primary amines.

Preceded by differential scanning calorimetry measurements for the determination of the glass-transition temperatures (not reported herein) and the calculation of the surface energy from contact-angle measurements (not reported herein), further physicochemical characterization focused on the thermal conductivity of the resins and the composites, which was quantified by Guarded Heat Flow Meter measurements at 30, 60, 90, 120,150 , and $180^{\circ} \mathrm{C}$.

The resins and composites based on the BADGE monomer have thermal conductivities in the range from 0.15 to $0.20 \mathrm{~W} \cdot \mathrm{m}^{-1} \cdot \mathrm{K}^{-1}$ (Figure 2). In all BADGE-based specimens, the increase of the DAN content, which adds biphenyl units to the network structure, does 
not significantly enhance the thermal conductivity. Analogously, the increase of the temperature (above the glass-transition temperature) does not significantly alter the thermal conductivity of the BADGE-based specimens.
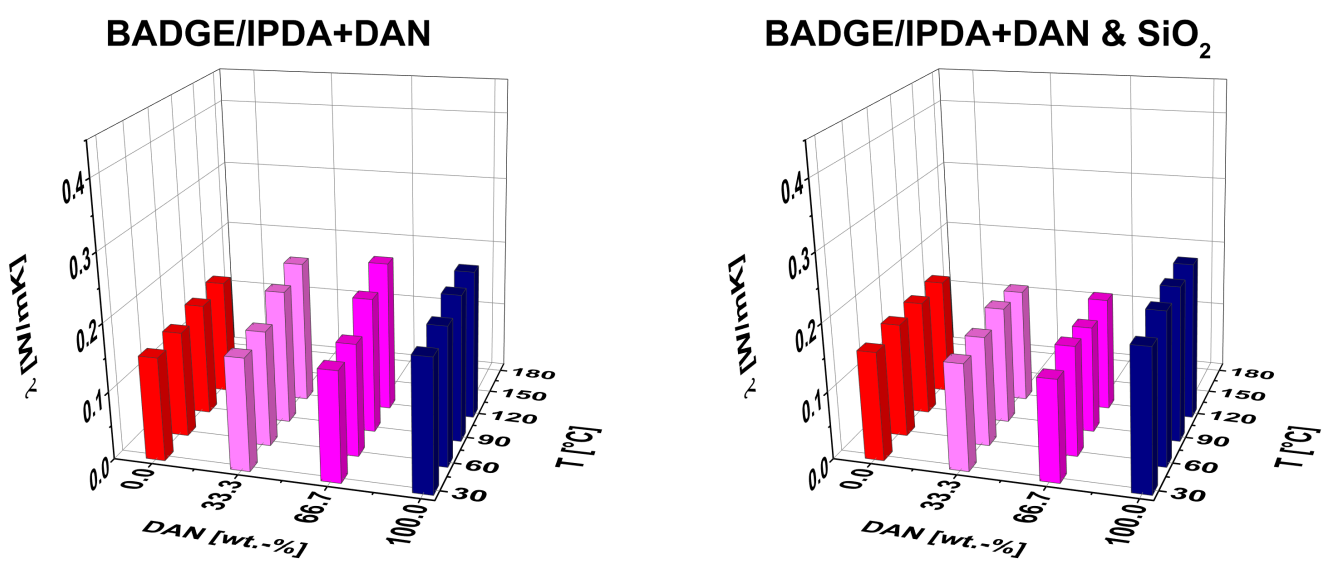

Figure 2. Thermal conductivities of unfilled BADGE-based resins (left) and the corresponding nanocomposites (right). (The Z-scales of Figures 2 and 3 were drawn to the same height.)

The thermal conductivities of the resins and composites based on DEO, by opposite, correlate with the temperature and absence/presence of inorganic particles: At $30^{\circ} \mathrm{C}$, the thermal conductivity of the resins as well as the composites covers a pronouncedly low range of only 0.08 to $0.15 \mathrm{~W} \cdot \mathrm{m}^{-1} \cdot \mathrm{K}^{-1}$. Starting from elevated temperatures of $90{ }^{\circ} \mathrm{C}$, the specimens that contain low amounts of DAN (0 and 33 wt.-\%) show no significant alteration of the thermal conductivity. On the other hand, the thermal conductivity of resins with high amounts of DAN (67 and $100 \mathrm{wt} . \%$ ) is increased. This increase of the thermal conductivity is more pronounced in the resins that were cured with DAN only. Above $120^{\circ} \mathrm{C}$, the thermal conductivity does not further increase. By contrast, the composites filled with silica nanoparticles reproduce this trend to lesser extent.
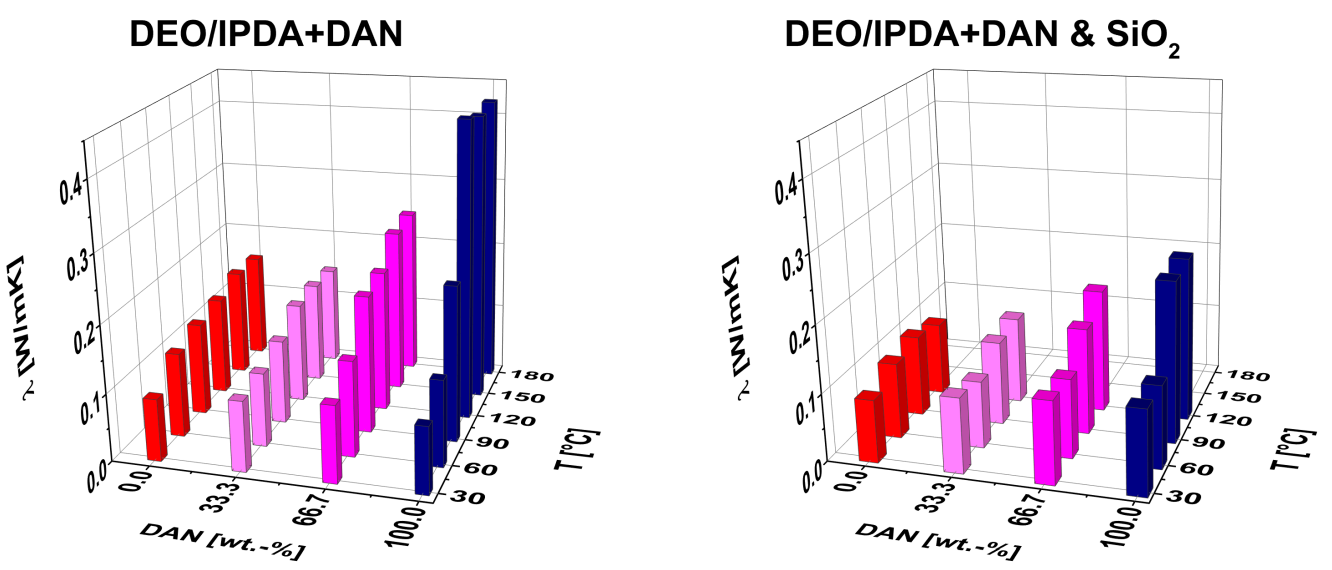

Figure 3. Thermal conductivities of the 1,2,7,8-diepoxy octane (DEO)-based resins (left) and the corresponding nanocomposites (right). (The Z-scales of Figures 2 and 3 were drawn to the same height.)

\section{Discussion}

The DEO-based resins and composites with 67 and 100 wt.-\% of DAN exclusively exhibit increased thermal conductivity at elevated temperatures starting from $90^{\circ} \mathrm{C}$. This observation is likely to originate from $\pi-\pi$ stacking of the biphenyl units of the DAN repetition unit: (i) The thermal conductivity increases in particular above $90^{\circ} \mathrm{C}$, hence, above 
the glass-transition temperature (not reported herein), above which the segmental mobility increases. Correspondingly, above $120^{\circ} \mathrm{C}$, the thermal conductivity does not increase further. (ii) In contrast to the unfilled resins, the silica -filled DEO-based composites show comparably lower thermal conductivities, which can be retraced to hindrance of the $\pi-\pi$ stacking due to the presence of the inorganic fillers (Figure 4).

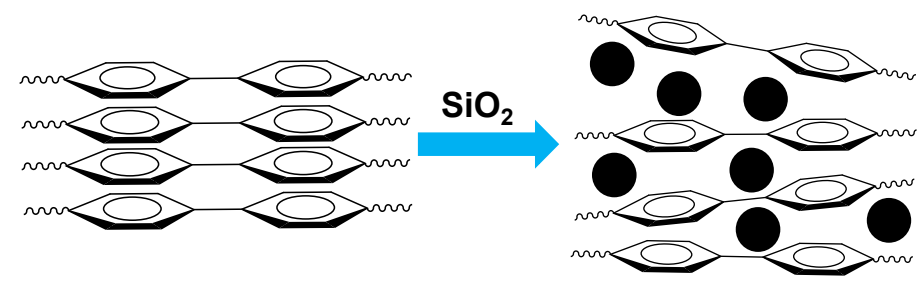

Figure 4. Disorder of the $\pi-\pi$ stacking due to the addition of silica nanoparticles.

In contrast to the DEO-based resins and composites, the BADGE-derived analogues exhibit comparably high rigidity. The epoxy monomer has little flexibility due to the aromatic groups in the main chain. As the BADGE-containing resins and composites do not show any significant increase of the thermal conductivity, the formation of anisotropic units is assumed not be achieved due to insufficient mobility of the polymer chain.

\section{Conclusions}

$\pi-\pi$ Stacking preferably occurs in the DEO-based resins and composites. The aliphatic chains of DEO are more flexible (in comparison to those of BADGE) and, hence, facilitate the alignment and the $\pi-\pi$ stacking of the biphenyl units of the crosslinker DAN. Nanoparticles disrupt the $\pi-\pi$ stacking of the biphenyl groups. BADGE-based epoxy resins, on the other hand, do not show any significant increase of the thermal conductivity, since the aromatic main chain has insufficient flexibility.

Notably, DEO can be derived from $p$ seudo-pelletierine, which is contained in the bark of the pomegranate tree. By using DEO as epoxy compound, resins and composites with competitive properties such as enhanced thermal conductivity can be prepared.

Author Contributions: M.S.W. and E.D. performed the lab-scale preparation of the test specimens; M.S.W. completed the physicochemical analyses; M.S.W. and F.W. discussed the data and compiled the manuscript. All authors have read and agreed to the published version of the manuscript.

Institutional Review Board Statement: Not applicable.

Informed Consent Statement: Not applicable.

Data Availability Statement: The data presented in this study are available on request from the corresponding author. The data are not yet publicly available due to the performance of on-going studies of the scientific findings that have been reported.

Acknowledgments: The research work was performed within the K-Project "PolyTherm" at the Polymer Competence Center Leoben GmbH (PCCL, Austria) within the framework of the COMET-program of the Federal Ministry for Climate Action, Environment, Energy, Mobility, Innovation and Technology and the Federal Ministry for Digital and Economic Affairs with contributions by the Graz University of Technology. Funding is provided by the Austrian Government and the State Government of Styria.

Conflicts of Interest: The authors declare no conflict of interest.

\begin{tabular}{|c|c|}
\hline Abbrev & \\
\hline The foll & reviations are used in this \\
\hline BADGE & bisphenol A diglycidyl ether \\
\hline DEO & $1,2,7,8$-diepoxy octane \\
\hline DAN & $o$-dianisidine \\
\hline
\end{tabular}


IPDA

isophorone diamine

\section{References}

1. Toshikatsu, T.; Montari, G.C.; Mülhaupt, R. Polymer nanocomposites as dielectrics and electrical insulation-perspectives for processing technologies, material characterization and future applications. IEEE Trans. Dielectr. Electr. Insul. 2004, 11, 763-784, doi:10.1109/TDEI.2004.1349782.

2. Camargo, P.H.C.; Satyanarayana, K.G.; Wypych, F. Nanocomposites: Synthesis, structure, properties and new application opportunities. Mater. Res. 2009, 12, 1-39, doi:10.1590/S1516-14392009000100002.

3. Hua, Z.; Shishan, W.; Shen, J. Polymer/silica nanocomposites: Preparation, characterization, properties, and applications. Chem. Rev. 2008, 108, 3893-3957, doi:10.1021/cr068035q.

4. Jiao, J.; Liu, P.; Wang, L.; Cai, Y. One-Step Synthesis of improved silica/epoxy nanocomposites with inorganic-organic hybrid network. J. Polym. Res. 2013, 20, 202, doi:10.1007/s10965-013-0202-9.

5. Kish, L.B. End of Moore's Law: Thermal (noise) death of integration in micro and nano electronics. Phys. Lett. A 2002, 305, 144149, doi:10.1016/S0375-9601(02)01365-8.

6. Krishnan, S.; Garimella, S.; Gregory, C.; Mahajan, R. Towards a Thermal Moore's Law. IEEE Trans. Adv. Packag. 2007, 30, 462474, doi:10.1109/TADVP.2007.898517.

7. Moradi, S.; Calventus, Y.; Roman, F.; Hutchinson, J. Achieving high thermal conductivity in epoxy composites: Effect of boron nitride particle size and matrix-filler interface. Polymers 2019, 11, 1156, doi:10.3390/polym11071156.

8. Singha, S.; Thomas, J. Dielectric properties of epoxy nanocomposites. IEEE Trans. Dielectr. Electr. Insul. 2008, 15, 12-23, doi:10.1109/T-DEI.2008.4446732.

9. Hu, J.; Huang, Y.; Zeng, X.; Qiang, L.; Ren, L.; Sun, R.; Xu, J.-B.; Wong, C.-P. Polymer Composite with enhanced thermal conductivity and mechanical strength through orientation manipulating of BN. Comp. Sci. Technol. 2018, 160, 127-137, doi:10.1016/j.compscitech.2018.01.045.

10. Nelson, K.J. Dielectric Polymer Nanocomposites, 1st ed.; Springer: New York, NY, USA, 2010.

11. Tanaka, T. Dielectric nanocomposites with insulating properties. IEEE Trans. Dielectr. Electr. Insul. 2005, 12, 914-928, doi:10.1109/TDEI.2005.1522186.

12. Siddabattuni, S.; Schuman, T.P.; Dogan, F. Dielectric Properties of Polymer-Particle Nanocomposites Influenced by Electronic Nature of Filler Surfaces. Appl. Mater. Interf. 2013, 5, 1917-1927, doi:10.1021/am3030239.

13. Wu, Y.; Zhang, X.; Negi, A.; He, J.; Hu, G.; Tian, S.; Liu, J. Synergistic Effects of Boron Nitride (BN) nanosheets and Silver (Ag) Nanoparticles on Thermal Conductivity and Electrical Properties of Epoxy Nanocomposites. Polymers 2020, 12, 426, doi:10.3390/polym12020426.

14. Gu, J.; Zhang, Q.; Dang, J.; Xie, C. Thermal conductivity epoxy resin composites filled with boron nitride. Polym. Adv. Technol. 2012, 23, 1025-1028, doi:0.1002/pat.2063.

15. Kuang, Z.; Chen, Y.; Lu, Y.; Liu, L.; Hu, S.; Wen, S.; Mao, Y.; Zhang, L. Fabrication of Highly Oriented Hexagonal Boron Nitride Nanosheet/Elastomer Nanocomposites with High Thermal Conductivity. Small 2015, 11, 1655-1659, doi:10.1002/smll.201402569.

16. Huang, X.; Jiang, P.; Tanaka, T. A Review of dielectric polymer composites with high thermal conductivity. IEEE Electr. Insul. Mag. 2011, 27, 8-16, doi:10.1109/MEI.2011.5954064.

17. Andritsch, T.; Kochetov, R.; Gebrekiros, Y.T.; Lafont, U.; Morshuis, P.H.F.; Smit, J.J. Synthesis and dielectric properties of epoxy based nanocomposites. IEEE Conf. Electr. Insul. Dielectr. Phenom. 2009, 523-526, doi:10.1109/CEIDP.2009.5377771.

18. Xiao, C.; Chen, L.; Tang, Y.; Zhang, X.; Zheng, K.; Tian, X. Enhanced thermal conductivity of silicon carbide nanowires (SiC)/epoxy resin composite with segregated structure. Compos. Part A Appl. Sci. Manuf. 2019, 116, 98-105, doi:10.1016/j.compositesa.2018.10.023.

19. Kozako, M.; Okazaki, Y.; Hikita, M.; Tanaka, T. Preparation and evaluation of epoxy composite insulating materials toward high thermal conductivity. In Proceedings of the 10th IEEE International Conference on Solid Dielectrics, Potsdam, Germany, 4-9 July 2010; Volume 10, pp. 1-4, doi:10.1109/ICSD.2010.5568250.

20. Zhang, Y.; Rhee, K.Y.; Hui, D.; Park, S.-J. A critical review of nanodiamond based nanocomposites: Synthesis, properties and applications. Compos. Part B Eng. 2018, 143, 19-27, doi:10.1016/j.compositesb.2018.01.028.

21. Zhang, Y.; Choi, J.-R.; Park, S.-J. Thermal conductivity and thermo-physical properties of nanodiamond-attached exfoliated hexagonal boron nitride/epoxy nanocomposites for microelectronics. Compos. Part A Appl. Sci. Manuf. 2017, 101, 227-236, doi:10.1016/j.compositesa.2017.06.019.

22. Morak, M.; Marx, P.; Gschwandl, M.; Fuchs, P.F.; Pfost, M.; Wiesbrock, F. Heat dissipation in epoxy/amine-based gradient composites with alumina particles: A critical evaluation of thermal conductivity measurements. Polymers 2018, 10, 1131, doi:10.3390/polym10101131. 
23. Yung, K.C.; Liem, H. Enhanced thermal conductivity of boron nitride epoxy-matrix composite through multi-modal particle size mixing. J. Appl. Polym. Sci. 2007, 106, 3587-3591, doi:10.1002/app.27027.

24. Kochetov, R.; Korobko, A.V.; Andritsch, T.; Morshuis, P.H.; Picken, S.J.; Smit, J.J. Modelling of the thermal conductivity in polymer nanocomposites and the impact of the interface between filler and matrix. J. Phys. D Appl. Phys. 2011, 44, 395-401, doi:10.1088/0022-3727/44/39/395401.

25. Peng, W.; Huang, X.; Yu, J.; Jiang, P.; Liu, W. Electrical and thermophysical properties of epoxy/aluminium nitride nanocomposites: Effects of nanoparticle surface modification. Compos. Part A Appl. Sci. Manuf. 2010, 41, 1201-1209, doi:10.1016/j.compositesa.2010.05.002.

26. Liu, Y.; Gao, S.; Gong, X.; Xue, Q.; Lu, Z. Benzoxazine-epoxy thermosets with smectic phase structures for high thermal conductive materials. Liq. Cryst. 2019, 46, 1686-1695, doi:10.1080/02678292.2019.1595755.

27. Chen, G.; Zhang, Q.; Hu, Z.; Wang, S.; Wu, K.; Shi, J.; Liang, L.; Mangeng, L. Liquid crystalline epoxides bearing biphenyl ether and aromatic ester mesogenic units: Synthesis and thermal properties. J. Macromol. Sci. Part A Pure Appl. Chem. 2019, 56, 484495, doi:10.1080/10601325.2019.1581578.

28. Yoshihara, S.; Kazuaki, M. Thermally-Conductive Organic Aditive, Resin Composition, and Cured Product. U.S. Patent No. 9,234,095, 2016.

29. Guo, H.; Zheng, J.; Gan, J.; Liang, L.; Wu, K.; Lu, M. High thermal conductivity epoxides containing substituted biphenyl mesogenic. J. Mater. Sci. Mater. Electr. 2016, 27, 2754-2759, doi:10.1007/s10854-015-4087-8.

30. Awais, M.; Sundarajan, R.; Sajjad, I.A.; Haroon, S.S.; Amin, S.; Shaukhat, H.; Nasir, M.A. Investigation of optimal filler loadings for dielectric strength enhancement of epoxy/TiO $@ \mathrm{SiO}_{2}$ nanocomposite. Mater. Res. Expr. 2019, 6, 65709, doi:10.1088/20531591/ab0ef2.

31. Plesa, I.; Notingher, P.; Stancu, C.; Wiesbrock, F.; Schlögl, S. Polyethylene Nanocomposites for Power Cable Insulations. Polymers 2019, 11, 24, doi:10.3390/polym11010024. 